\title{
Two Huntington Sonnets
}

... (Adorno's) material aesthetic reflects its own historicity and admits that even the most important work depends on the work of its predecessors, which is stored in its material.

(Peter Burger, 'The Problem of Aesthetic Value')

Huntington's purified by manuscripts

moldering delicately under glass.

The penmanship of Pope or Swift equips

us with material too dense to pass

for continuity; the looping $j$ 's

the showy l's, bracket reality

with words, and ply with faintly static praise

those curators who tend fatality.

The guard's immobile chin insists values

have trans-historical validity.

Books pressed like asters by humidity,

the scripts dissolve to sluggish curly-cues.

Lavender clusters of wisteria

assault the sills, a massed hysteria.

The Zen and Desert Gardens are so groomed one prefers a bench between gardens, where the meaning of an afternoon affair allows historicity unsubsumed

by form. For this exchange, the meaning comes from your wife, sipping tea with Portland aunts, and from the men I've known whose needs or wants do not resemble yours. That last kiss sums it up - don't speak for fear the utterance will script calligraphy with ornament.

The motion that we saved, those lovers spentin the Jungle Garden, a consequence of desire that seeks scones and Perrier.

They'll shoot like bamboo, six inches a day. 